\title{
EXAMINATION OF IN VITRO WOUND HEALING ANTIMICROBIAL ACTIVITY OF EXTRACT OF SELECTED MEDICINAL PLANTS
}

\author{
CHANDUKISHORE T*, SAMSKRATHI D, SRUJANA TL
}

\author{
Department of Biotechnology, Research Centre, Bapuji Institute of Engineering and Technology, Davangere, Karnataka, India. \\ Email: chandukishore.cvkt.22@gmail.com
}

Received: 27 November 2019, Revised and Accepted: 24 December 2019

\begin{abstract}
Objective: The objective of this study was to discover and examine the in vitro wound healing activity of selected medicinal plants against common wound infecting microorganisms.
\end{abstract}

Methods: Ziziphus rugosa and Hemidesmus indicus plant parts were used for aqueous and solvent extract preparation, maceration technique was followed. In vitro antibiotic test has been done using disc diffusion method.

Results: Maximum yield for aqueous extract was observed in Z. rugosa bark sample (50.6\%) and minimum yield was noted in $H$. indicus leaf extract in $(45.7 \%)$ and maximum yield in solvent extract was observed in methanol extract of $Z$. rugosa (37.5\%) whereas minimum yield was observed in of acetone extract of leaves of $Z$. rugosa (25\%). For all sample extracts tested, leaf extract of acetone and methanol extract of $Z$. rugosa and $H$. indicus showed the highest antibiotic zone of inhibition of $15 \mathrm{~mm}$ and $12 \mathrm{~mm}$, whereas lowest zone of inhibition was observed in aqueous bark extract of $Z$. rugosa (7 mm).

Conclusion: Crude aqueous and solvent extract of selected plant were showed that promising results have a wound healing aid, efficacy of which could be further improved by studying and practicing more advanced extraction procedure for future prospectus.

Keywords: Extraction, Hemidesmus indicus, Wound healing, Ziziphus rugosa, Zone of inhibition.

(C) 2020 The Authors. Published by Innovare Academic Sciences Pvt Ltd. This is an open access article under the CC BY license (http://creativecommons. org/licenses/by/4. 0/) DOI: http://dx.doi.org/10.22159/ajpcr.2020.v13i2.36475

\section{INTRODUCTION}

In India, there are about 47,000 plant species and they are distributed in various vegetation zones. The history of using medicinal plants in the herbal treatment of various contagious diseases goes back to medieval times which also possesses active components which can be used as a replacement to potent and beneficial herbal drugs against common bacterial infections [1]. Phytomedicine is used for primary health care around $80 \%$ of the world population. In 1991, the World Health Organization developed general instructions for assessment of phytomedicine, the turnover of phytomedicine in India as standard formulations and home remedies of Ayurvedic medicine system. Various microbial infections render health issues all over the mankind and other organisms where plants act as a valuable source of antimicrobial agents [2].

Ziziphus rugosa Lam. (Rhamnaceae), a large spreading climber armed shrub with large elliptic usually subcordate leaves, paniculate flowers and wood is reddish, moderately hard and fruit is small drupe, glabrous, white when ripe. The bark contains quercetin, betulin, betulinic acid, vanillic acid, myricetin, kaempferol, apigenin-7-0glucoside, and apigenin [3]. The bark also contains several $\mathrm{N}$-formyl cyclopeptide alkaloids. The isolation of triterpene saponins from the bark showed analgesic and tranquilizing activity in albino rats and produced no hepatotoxicity. Bark possess strong astringent and antidiarrheal properties various works posted that this plant shows anti-inflammatory, anxiolytic, central nervous system (CNS) depressant, antifungal, cytotoxic, antibacterial, analgesic, antioxidant, and antimicrobial properties. Hemidesmus indicus is commonly called as Indian sarsaparilla which belongs to the family of Periplocaceae thus known as Periploca indica [4,5]. H. indicus has been used as a folk medicine for a long time and found to be an important part of Ayurvedic and Unani medicine. It is a perennial climber found in the eastern and southern parts of India [6]. It is a slender, laticiferous, and endangered shrub that is specifically known for its immense medicinal values; for example, antivenom, antiarthritic, antimicrobial, antiulcer, antileprotic, anticancerous, hepatoprotective, immunomodulatory, wound healing property, etc. The immense medicinal values of $H$. indicus can be considered as a royal source of herbal medicine in India $[7,8]$.

In the present study, various crude aqueous and solvent extract of two selected medicinal plants samples of Z. rugosa and H. indicus were prepared and tested for in vitro antimicrobial sensitivity against commonly wound infecting organisms by isolating microbes from wound infected samples by disc diffusion method and measurement of inhibition zone if found $[9,10]$.

\section{MATERIALS AND METHODS}

\section{Material}

The two medicinal plants Z. rugosa and H. indicus were selected for the antimicrobial study based on their literature study and their usage as home remedies for wound healing and anti-inflammatory property across various parts of Western Ghats of Uttar Kannada district of Karnataka from where they have been collected for the study. Their botanical identities were determined and authenticated in the Botany Department of Shivagangothri Campus located at Tolahunase, Davangere University, Davangere.

\section{Preparation of plant extract}

Maceration technique was followed to prepare the aqueous and solvent extract of selected plants. For the extract preparation, selected plant parts such as leaves and bark were isolated from a whole plant and were further cleaned using running water to remove dirt and grit. The cleaned plant parts were sterilized and air-dried. The dried plant samples were grinded in electronic mixer blender to obtain dried powdered samples for further preparation of plant extract. 


\section{Aqueous extraction}

The powdered samples were mixed with distilled water at a ratio of 1:10 (g/ml). The mixture was filtered and boiled to an extent that a dense liquid formed. The filtered liquid was then centrifuged at $6000 \mathrm{rpm}$ for 10 $\min$ at $4^{\circ} \mathrm{C}$ and the supernatant was isolated and stored for further testing.

\section{Solvent extraction}

For solvent extraction, methanol and acetone were considered. Primarily prepared air-dried powdered plant samples were dissolved in solvent at a ratio of $1: 8(\mathrm{~g} / \mathrm{ml})$. The mixture was kept for incubation in shaker incubator for $38^{\circ} \mathrm{C}$ at $140 \mathrm{rpm}$ for $72 \mathrm{~h}$. The mixture was then filtered and boiled until the extract became dense. The supernatant was collected and stored [11].

\section{Antimicrobial assay}

\section{Bacterial culture preparation}

The wound infected dressing samples were collected from nearby hospitals which included dressings of diabetes patients infected wounds and accidental injury wounds. Using sterile swabs, nutrient broth has been inoculated with above-mentioned samples and incubated at room temperature to obtain $10^{8} \mathrm{CFU} / \mathrm{ml}$ of density.

\section{Disc diffusion assay}

For the disc diffusion assay, nutrient agar plates were prepared and spread plate method was followed for even distribution of bacterial culture prepared and isolated from wound infected samples on a solidified nutrient media. From a sheet of Whatman Filter paper, discs of $6 \mathrm{~mm}$ diameter were punched, sterilized and were made to absorb $20 \mu \mathrm{l}$ each of $20 \mu \mathrm{g} / \mathrm{ml}$ and were air-dried at $37^{\circ} \mathrm{C}$ for $48 \mathrm{~h}$ and thereafter, the discs were placed on the surface of inoculated nutrient agar plates, and then incubated at $37^{\circ} \mathrm{C}$ for $24-48 \mathrm{~h}$ to observe formation of inhibition zones around the discs [12].

\section{Determination of minimum inhibitory concentration (MIC)}

The MIC of the plant extracts was determined by concentrated dilutes of various plant extracts. The extracts and nutrient broth were taken in equal volume and mixed in the test tube. Standardized inoculums of $1-2 \times 10^{7} \mathrm{CFU} / \mathrm{ml}$ of $0.1 \mathrm{ml}$ were added to each tube. The tubes were incubated aerobically at $37^{\circ} \mathrm{C}$ for $19-25 \mathrm{~h}$. For each test batch, two control tubes were maintained. This is as follows: Tube containing extracts and the growth medium without inoculums (antibiotic control) and the tube containing the growth medium, physiological saline, and the inoculums (organism control). MIC was determined as the lowest concentration of the extracts permitting no visible growth (no turbidity) when compared with the control tubes [13].

\section{Statistical analysis}

The statistical analysis was done using one-way ANOVA (Microsoft Excel 2007), each experiment was set up with triplicates and the data were represented as mean \pm standard error. Data were analyzed by ANOVA $(\mathrm{p} \leq 0.05) . \mathrm{p}<0.05$ was considered statistically significant.

\section{RESULTS}

\section{Yield of extraction}

Yield of extraction of various organic and solvent plant extracts was examined. The yields varied from different plant extracts during extraction. Maximum yield for aqueous extract was observed in Z. rugosa bark sample $(50.6 \%)$ and minimum yield was noted in $H$. indicus leaf extract in (45.7\%) and maximum yield in solvent extract was observed in methanol extract of $Z$. rugosa $(37.5 \%)$ whereas minimum yield was observed in of acetone extract of leaves of Z. rugosa (25\%) [14]. Further yields of various plant extracts were tabulated in Table 1.

Extraction yield: The yield of extracts of different plants studied. Yield of extract $=$ Obtained extract/total solid sample used

\section{Determination of antimicrobial assay and MIC}

Aqueous and solvent extract samples of two selected plants were prepared and further tested for antibacterial property against bacterial cultures isolated from three different wound infected bandage samples. Disc diffusion method was followed for which in general organic solvent extract samples showed promising results compared to aqueous extract. For all sample extracts tested, leaf extract of acetone and methanol extract of $Z$. rugosa and H. indicus showed highest antibiotic zone of inhibition of $15 \mathrm{~mm}$ and $12 \mathrm{~mm}$ whereas the lowest zone of inhibition was observed in aqueous bark extract of Z. rugosa $(7 \mathrm{~mm})$ and various other zones of inhibition for plant extract against wound infected cultures were tabulated in Table 2 [15].

MIC test was also performed against selected commonly wound infecting organisms such as Staphylococcus aureus, Pseudomonas aeruginosa, Escherichia coli, and Klebsiella pneumoniae which were identified and cultured from bacterial cultures isolated from wound infected samples and confirmed by biochemical methods. MIC values were obtained from aqueous and organic solvent plant extracts that show antibacterial activity, which range between 0.1 and $0.775 \mathrm{mg} / \mathrm{ml}$, the best MIC values were noted in the $H$. indicus solvent extract against $P$. aeruginosa culture $(0.090 \mathrm{mg} / \mathrm{ml})$ and least, unsatisfactory MIC was noted against $S$. aureus for $Z$. rugosa plant extract $(0.750 \mathrm{mg} / \mathrm{ml})$; further, MIC values other plant extracts against each organism are shown in Table 3 [16].

Antimicrobial potential of plants has been used since ages as a cure for many contagious diseases in humans. The ethnobotanical information of these Indian plant species selected for antibacterial activity is given in Table $4[17,18]$.

\section{DISCUSSION}

Wound healing of cut wounds, burn wounds, and diabetic wounds which are type of cutaneous wounds generally exposed to environment and readily get infected by various types of microbes. In general, wound infected samples were isolated to find out major contributors of microbial infection such studies evidenced to found a common group of bacterial load such as E. coli, S. aureus, P. aeruginosa, and K. pneumoniae. Burn injuries are open wounds and render a dangerous threat to burn victims, mostly those with wide areas exposed [19]. This is the foremost cause of dehydration, systemic infection, and other hurdles experienced by burns affected patients. One of the crucial factors for successful treatment of various open wounds in victims is to lock the injury at the earliest. Contamination, either by bacteria or fungi, can give on to worsening of the wound healing process and several other problems [20]. The use of plant-based extract which possesses notable antibacterial agents locally or systemically can contribute to wound healing, especially for cutaneous wounds. Most modern antibiotics trigger various side effects and accumulation of drugs which can be replaced by plant-based organic and natural antibiotic compounds.

Table 1: Yield of extract of aqueous and solvent extraction of plant samples

\begin{tabular}{lllc}
\hline Plant species & Part of plant & \multicolumn{2}{l}{ Yield of extraction (\%) } \\
\cline { 3 - 4 } & & Aqueous & Methanol \\
\hline Z. rugosa & Leaves & $7.2 \mathrm{ml} / 15 \mathrm{~g}=48$ & $3 \mathrm{ml} / 8 \mathrm{~g}=37.5$ \\
Z. rugosa & Bark & $7.6 \mathrm{ml} / 15 \mathrm{~g}=50.6$ & $7 \mathrm{ml} / 20 \mathrm{~g}=35$ \\
Hemidesmus indicus & Leaves & $3.2 \mathrm{ml} / 7 \mathrm{~g}=45.7$ & $2.9 \mathrm{ml} / 10 \mathrm{~g}=29$ \\
\hline
\end{tabular}


Table 2: Plant extract antimicrobial activity and length of zone of inhibition

\begin{tabular}{|c|c|c|c|c|c|}
\hline \multirow[t]{2}{*}{ Plant species } & \multirow[t]{2}{*}{ Part of the plant used } & \multirow[t]{2}{*}{ Plant extract } & \multicolumn{3}{|c|}{$\begin{array}{l}\text { Antibiotic inhibition zone (bacteria culture isolated from different wound } \\
\text { infected samples) }\end{array}$} \\
\hline & & & Culture 1 (mm) & Culture $2(\mathrm{~mm})$ & Culture 3 (mm) \\
\hline \multirow{5}{*}{ Ziziphus rugosa } & Leaf & Methanol & 12 & 10 & 7 \\
\hline & & Acetone & 15 & 11 & 12 \\
\hline & & Water & 8 & 9 & 8 \\
\hline & Bark & Methanol & 9 & 8 & 9 \\
\hline & & Water & 7 & 8 & 7 \\
\hline \multirow[t]{3}{*}{ Hemidesmus indicus } & Leaf & Methanol & 10 & 8 & 11 \\
\hline & & Acetone & 12 & 10 & 11 \\
\hline & & Water & $\begin{array}{l}\text { No significant inhibition } \\
\text { zone found }\end{array}$ & $\begin{array}{l}\text { No significant inhibition } \\
\text { zone found }\end{array}$ & $\begin{array}{l}\text { No significant inhibition } \\
\text { zone found }\end{array}$ \\
\hline
\end{tabular}

Table 3: Minimum inhibitory concentration values for plant extract against wound infecting microbes

\begin{tabular}{|c|c|c|c|c|c|}
\hline \multirow[t]{3}{*}{ S. No. } & \multirow[t]{3}{*}{ Microorganisms } & \multicolumn{4}{|c|}{ Minimum inhibitory concentration $(\mathrm{mg} / \mathrm{ml})$} \\
\hline & & \multicolumn{2}{|l|}{ Aqueous extract } & \multicolumn{2}{|c|}{ Organic solvent extract } \\
\hline & & Ziziphus rugosa & Hemidesmus indicus & Ziziphus rugosa & Hemidesmus indicus \\
\hline 1. & Staphylococcus aureus & 0.750 & 0.200 & 0.600 & 0.100 \\
\hline 2. & Pseudomonas aeruginosa & 0.625 & 0.090 & 0.700 & 0.085 \\
\hline 3. & Escherichia coli & 0.700 & 0.250 & 0.675 & 0.250 \\
\hline 4. & Klebsiella pneumoniae & 0.660 & 0.220 & 0.700 & 0.190 \\
\hline
\end{tabular}

Table 4: Therapeutic importance of various parts of $Z$. rugosa and $H$. indicus

\begin{tabular}{|c|c|c|c|c|}
\hline Plant species & Family & Common name & Part of plant & Therapeutic importance \\
\hline Z. rugosa & Rhamnaceae & Zunna berry & Leaf & Analgesic, anti-inflammatory, antibacterial, antifungal, anxiolytic \\
\hline Z. rugosa & Rhamnaceae & Zunna berry & Bark & Central nervous system depressant, cytotoxic, antimicrobial \\
\hline H. indicus & Periplocaceae & Anantmool & Leaf & Antiarthritic, antimicrobial, antiulcer, antivenom, antileprotic \\
\hline H. indicus & Periplocaceae & Anantmool & Bark & Immunomodulatory, hepatoprotective, wound healing activity \\
\hline
\end{tabular}

Z. rugosa: Ziziphus rugosa, H. indicus: Hemidesmus indicus

Their utilization hinders microbial growth on site of infection or around the injury and renders a need able microenvironment for healing [21].

Further, more refined plant extraction procedure needs to be followed to produce pure antibiotic samples for stronger zone of inhibition and better wound healing of burns and wounds. Although in vitro examination was successful to an extent, in vivo acceptability needs an in-depth study of various aspects of raw material selection, selection of organic solvent, solvent-sample ratio, and different stages of purification procedures in large scale production [22].

\section{CONCLUSION}

Plant-based phytochemical extraction procedures have various challenges in in vivo treatment of wound healing applications. In general, selected medicinal plants such as Z. rugosa and H. indicus have already showed various property of hepatoprotective, CNS depressant, antiarthritic, analgesic, anti-inflammatory, antimicrobial, antifungal, and antivenom property by its various phytochemical constituents which need to isolated in manner which is economical and with more efficacy for successful usage and large scale sustainable production of plant extract as antimicrobial compounds for wound healing applications.

\section{AUTHORS' CONTRIBUTIONS}

We declare that this work was done by the authors named in this article and all liabilities pertaining to claims relating to the content of this article will be borne by the authors. Ms. Samskrathi D contributed to the collection of the plant sample; Ms. Samskrathi D and Ms. Srujana TL have carried out extraction and antibiotic testing to measure the diameter of inhibition zone; and Mr. Chandukishore T contributed to the study guide and coordinated the manuscript writing, editing, and finalization of results. All authors discussed the results and contributed to the final manuscript.

\section{CONFLICTS OF INTEREST}

The authors declare that there are no conflicts of interest regarding the publication of this paper.

\section{SOURCE OF FUNDING}

Nil.

\section{REFERENCES}

1. Sathishkumar. Ethnnomedicinal plants of Gopalswamy hills, Western Ghats, Coimbatore District, Tamil Nadu. Int J Plant Anim Environ Sci 2019;9:6-12.

2. Vinayaka KS, Ravindra P, Kumaraswamy HG. Nutritive composition of fruit of Ziziphus rugosa Lam. Res Artic 2011;2:20-4.

3. Banerjee A, Ganguly S. Medicinal importance of Hemidesmus indicus: A review on its utilities from ancient ayurveda to $20^{\text {th }}$ century. Adv Biores 2014;5:208-13.

4. Weissner W. Anantamul (Hemidesmus indicus): A review of biomedical studies and US products. Ayurveda J Health 2014;12:40-52.

5. Kekuda TR, Raghavendra HL, Vinayaka KS. Evaluation of pericarp and seed extract of Ziziphus rugosa Lam. for cytotoxic activity. Int J Pharm Biol Arch 2011;2:887-90.

6. Chatterjee S, Banerjee A, Chandra I. Hemidesmus indicus: A rich source of herbal medicine. Med Aromat Plants 2014;3:e155.

7. Krishnamurthy SR, Sarala P. Determination of nutritive value of Ziziphus rugosa Lamk.: A famine edible fruit and medicinal plant of Western Ghats. Indian J Nat Prod Resour 2012;3:20-7.

8. Bulbul IJ, Khan MF, Rashid MA. Analgesic and central nervous system depressant activities of methanol extract of Ziziphus rugosa Lam. 
Leaves. Afr J Pharm Pharmacol 2016;10:849-53.

9. Abhimany Y, Pratiksha S. Analgesic and anti-inflammatory activities of Ziziphus rugosa root barks. J Chem Pharm Res 2010;2:255-9.

10. Njimoh DL, Assob JC, Mokake SE, Nyhalah DJ, Yinda CK, Sandjon B. Antimicrobial activities of a plethora of medicinal plant extracts and hydrolates against human pathogens and their potential to reverse antibiotic resistance. Int J Microbiol 2015;2015:547156.

11. Saif MM, Al-Fakih AA, Hassan MA. Antibacterial activity of selected plant (aqueous and methanolic) extracts against some pathogenic bacteria. J Pharm Phytochem 2017;6:1929-35.

12. Prashith KT, Vinayaka KS, Mallikarjun N, Bharath AC, Shailendra KB, Rakesh KM, et al. Antibacterial, insecticidal and free radical scavenging activity of methanol extract of Ziziphus rugosa Lam.(Rhamnaceae) fruit pericarp. Pharm J 2011;2:65-9.

13. Akinyemi KO, Oluwa OK, Omomigbehin EO. Antimicrobial activity of crude extracts of three medicinal plants used in South-West Nigerian folk medicine on some food borne bacterial pathogens. Afr J Tradit Complement Alternat Med 2006;3:13-22.

14. De Zoysa MH, Rathnayake H, Hewawasam RP, Wijayaratne WM. Determination of in vitro antimicrobial activity of five Sri Lankan medicinal plants against selected human pathogenic bacteria. Int J Microbiol 2019;2019:15.

15. Shoeb M, Mir M, Nahar N, Mosihuzzaman M. Biological screening of Ziziphus rugosa and Ziziphus oenoplia extractives. Dhaka Uni J Pharm Sci $2005 ; 4: 131-4$.
16. Sameera NS, Mandakini BP. Investigations into the antibacterial activity of Ziziphus mauritiana Lam. and Ziziphus xylopyrus (Retz.) willd. Int Food Res J 2015;22:849.

17. Darbari S, Agrawal A, Verma P, Rai TP, Garg R, Chaudhary SB. Antzimicrobial activity of root extracts of the medicinal plant Hemidesmus indicus (L.) R. Br. Var. Pubescens (W. And A.) H.K.F. World J Pharm Pharm Sci 2016;5:1556-62.

18. Kaleem WA, Muhammad N, Khan H, Rauf A. Pharmacological and phytochemical studies of genus Ziziphus. Middle East J Sci Res 2014;21:1243-63.

19. Kurapati VK, Nishteswar K. Phytochemical and clinical evaluation of Sariba (Hemidesmus indicus) on wound healing. Int Res J Pharm 2012;3:277-81

20. Gayathri M, Kannabiran K. Antimicrobial activity of Hemidesmus indicus, Ficus benghalensis and Pterocarpus marsupium roxb. Indian J Pharm Sci 2009;71:578-81.

21. Boyko N, Tkachev A, Kovalenko A, Pisarev D, Kuznietsova V, Sushchuk N, et al. Phytochemical, microbiological, and technological studies in the field of obtaining a hydroalcoholic extract with antimicrobial activity from the liquorice root. Asian J Pharm Clin Res 2019;12:403-7.

22. Jacob V, Rajiv P. In vitro analysis: The antimicrobial and antioxidant activity of zinc oxide nanoparticles from Curcuma longa. Asian J Pharm Clin Res 2019;12:200-4. 